Research paper

\title{
Adsorption of Acid Yellow 42 dye on calcined layered double hydroxide: Effect of time, concentration, $\mathrm{pH}$ and temperature
}

\author{
Rodrigo Morais Menezes dos Santos ${ }^{a}$, Rosembergue Gabriel Lima Gonçalves a , \\ Vera Regina Leopoldo Constantino ${ }^{\mathrm{b}}$, Celso Valentim Santilli ${ }^{\mathrm{c}}$, Pablo Damasceno Borges ${ }^{\mathrm{a}}$, \\ Jairo Tronto $^{\mathrm{a}, *}$, Frederico Garcia Pinto ${ }^{\mathrm{a}}$ \\ a Institute of Science and Technology, Federal University of Viçosa, Rio Paranaíba Campus, Rodovia BR 354 - km 310, CEP:38810-000 Rio Paranaíba, Minas Gerais, Brazil \\ b Department of Fundamental Chemistry, Institute of Chemistry, University of São Paulo, Av. Prof. Lineu Prestes 748, CEP:05508-000, São Paulo, São Paulo, Brazil \\ c Institute of Chemistry, UNESP - São Paulo State University, P.O. Box 355, CEP: 14800-900 Araraquara, São Paulo, Brazil
}

\section{A R T I C L E I N F O}

\section{Article history:}

Received 2 December 2016

Received in revised form 20 January 2017

Accepted 6 February 2017

Available online 14 February 2017

\section{Keywords:}

Adsorption

Memory effect

Intercalation

Dye

Recyclability

\begin{abstract}
A B S T R A C T
The adsorption of textile dyes onto Layered Double Hydroxides (LDH) and their thermally decomposed products is a promising strategy for the treatment of contaminated effluents - combining high removal efficiency with reasonable cost. The main purpose of this paper was to investigate the adsorption of textile azo dye Acid Yellow 42 (AY) onto calcined and uncalcined $\mathrm{Mg}-\mathrm{Al}-\mathrm{CO}_{3}-\mathrm{LDH}$. A set of analytical techniques was used to characterize the materials, namely X-ray diffraction (XRD), Attenuated Total Reflectance Fourier Transform Infrared Spectroscopy (ATR-FTIR), thermogravimetric analyses (TGA), $\mathrm{N}_{2}$ adsorption-desorption isotherms and Scanning Electron Microscopy (SEM). In the study of azo dye adsorption, the following factors were assessed: kinetics, adsorption capacity, effect of temperature, initial $\mathrm{pH}$ value, and recyclability of the adsorbent material. The adsorption capacity of calcined LDH (CLDH) was almost four times greater than that of the LDH precursor: $1266 \mathrm{mg} \cdot \mathrm{g}^{-1}$ $\left(1.669 \mathrm{mmol} \cdot \mathrm{g}^{-1}\right)$ and $330.0 \mathrm{mg} \cdot \mathrm{g}^{-1}\left(0.4350 \mathrm{mmol} \cdot \mathrm{g}^{-1}\right)$, respectively, at pH equal to 7.0 and $25^{\circ} \mathrm{C}$. The greater adsorption capacity for CLDH is related to the recovery property of these materials in light of the so called "memory effect", which allows an intercalation process of the anionic dye, as demonstrated by XRD data.
\end{abstract}

(c) 2017 Elsevier B.V. All rights reserved.

\section{Introduction}

The pollution of rivers and lakes by textile dyes has resulted in a series of environmental problems with serious consequences for fauna and flora. Approximately 100,000 kinds of dyes are available worldwide with annual production exceeding 10,00,000 tons (Robinson et al., 2001; Tan et al., 2015). During dye production and the dyeing process, about $15 \%$ of all dyes are disposed of in wastewaters, primarily due to incomplete fixation of the dye onto the fabric (Tan et al., 2015). Adsorption processes have been extensively studied for the removal of dyes from textile wastewaters. High removal efficiency, low cost of installation, and management are key factors in the implementation of adsorption processes on the industrial scale (Gupta and Suhas, 2009; Darmograi et al., 2015).

The Layered Double Hydroxides (LDH), also called hydrotalcite-like compounds, and their thermal decomposition products are receiving greater levels of interest in the removal of various contaminant species such as dyes, surfactants, agrochemicals, and inorganic anions from aqueous solutions (Dos Reis et al., 2004; Santos et al., 2013; Lu et al.,

\footnotetext{
* Corresponding author.

E-mail address: jairotronto@gmail.com (J. Tronto).
}

2015; Zhao et al., 2015). LDH can be described by the general formula $\left[\mathrm{M}_{1}^{\mathrm{II}}{ }_{-\mathrm{x}} \mathrm{M}_{\mathrm{x}}^{\mathrm{III}}(\mathrm{OH})_{2}\right] \mathrm{A}^{\mathrm{n}-}{ }_{\mathrm{x} / \mathrm{n}} \cdot m \mathrm{H}_{2} \mathrm{O}$, abbreviated as [ $\left.\mathrm{M}^{\mathrm{II}}-\mathrm{M}^{\mathrm{III}}-\mathrm{A}\right]$, where $\mathrm{M}^{\mathrm{II}}$ and $\mathrm{M}^{\mathrm{III}}$ are divalent and trivalent metal cations, $\mathrm{A}^{\mathrm{n}-}$ is the intercalated anion with $\mathrm{n}$ - electrical charge, and $m$ denotes the number of interlayer water molecules (Forano et al., 2013). The calcination of LDH at moderate temperatures $\left(400-550{ }^{\circ} \mathrm{C}\right)$ can lead to the formation of metastable mixed oxides. These mixed oxides demonstrate an interesting property known as the "memory effect", which is the recovery of the layered structure of LDH upon contact with water or aqueous solutions containing anions (Forano et al., 2013; Baskaran et al., 2015).

In literature, several studies have described the adsorption of dyes by LDH compounds (Jia et al., 2015; Shan et al., 2015; Koilraj et al., 2016; Yang et al., 2016). El Gaini et al. (2009) showed the efficiency of calcined MgAl-LDH in the removal of Indigo Carmine (IC) dye from aqueous solutions. The adsorbent material calcined at $600{ }^{\circ} \mathrm{C}$ showed the highest efficiency of dye removal, with a maximum adsorption capacity of $3.83 \mathrm{mmol} \cdot \mathrm{g}^{-1}$. The intercalation of the organic anion, as well as the recovery of the initial layered structure, was clearly evident by the peak dislocation $\mathrm{d}(003)$ from 0.76 to $2.13 \mathrm{~nm}$ (El Gaini et al., 2009).

In another study, Ni et al. (2007) reported the application of calcined ZnAl-LDH for the Methyl Orange (MO) dye adsorption. The maximum 
adsorption capacity was $0.56 \mathrm{mmol} \cdot \mathrm{g}^{-1}$. The recycling capacity tests of the adsorbent material (calcined LDH) showed, in repeated calcination/ adsorption cycles, that the material can be reused in more than three cycles with no significant loss of its adsorption capacity (Ni et al., 2007).

The main objectives of this work were to evaluate the potential for MgAl-LDH materials, in their uncalcined (LDH) and calcined (CLDH) forms, as adsorbents in the removal of Acid Yellow 42 azo dye from aqueous solutions. The effect of various factors such as kinetics, adsorption capacity, temperature, concentration, and initial $\mathrm{pH}$ value was studied. Furthermore, the recyclability of CLDH in repeated calcination/ adsorption cycles was assessed. The Acid Yellow 42 azo dye was chosen in this study because it is widely used in industry for dyeing wool, silk, polyamide fibers, and leather. Its presence in industrial textile effluents is highly damaging to the environment.

\section{Experimental}

\subsection{Materials}

Aluminum nitrate nonahydrate, magnesium nitrate hexahydrate, sodium hydroxide, sodium carbonate and hydrochloric acid were purchased from Sigma-Aldrich ${ }^{\circledR}$. Acid Yellow 42 dye (abbreviated as AY) was supplied by BASF Company (commercial name Luganil Yellow $G \circledR)$, Porto Alegre-RS, Brazil. The chemical structure and some characteristics of AY are reported in supplementary material (Table S1). The reagents - used as purchased without further purification - were all of analytical grade. All solutions were prepared with high purity deionized water.

\subsection{Preparation of the adsorbent materials}

LDH was prepared by a coprecipitation method at constant $\mathrm{pH}$ value as follows: a solution containing $\mathrm{Mg}\left(\mathrm{NO}_{3}\right)_{2} \cdot 6 \mathrm{H}_{2} \mathrm{O}(54.0 \mathrm{mmol})$ and $\mathrm{Al}\left(\mathrm{NO}_{3}\right)_{3} \cdot 9 \mathrm{H}_{2} \mathrm{O}(18.0 \mathrm{mmol})$ in water $(250 \mathrm{~mL})$ was added dropwise under vigorous stirring to a solution containing $\mathrm{Na}_{2} \mathrm{CO}_{3}(73.0 \mathrm{mmol})$ in water $(1000 \mathrm{~mL})$. A NaOH solution $\left(2.00 \mathrm{~mol} \cdot \mathrm{L}^{-1}\right)$ was added dropwise to keep the $\mathrm{pH}$ value constant at 10.0. The resulting slurry was aged at $65^{\circ} \mathrm{C}$ for $24 \mathrm{~h}$. After synthesis, the solid in suspension was washed with deionized water by centrifugation/resuspension cycles until the $\mathrm{pH}$ was 7 . The material was subsequently dried at reduced pressure in the presence of silica gel. To prepare the calcined LDH (abbreviated as CLDH), LDH was heated in a tubular furnace at $550{ }^{\circ} \mathrm{C}$ for $4 \mathrm{~h}$ under atmospheric air with a flow of $50 \mathrm{~mL} \cdot \mathrm{min}^{-1}$ and heating rate of $10^{\circ} \mathrm{C} \cdot \mathrm{min}^{-1}$.

\subsection{Synthesis of azo dye-intercalated $\mathrm{LDH}$}

AY-intercalated LDH (abbreviated as LDH-AY) was prepared by coprecipitation at a constant $\mathrm{pH}$ value of 10.0 under nitrogen atmosphere, avoiding the formation of carbonate-intercalated LDH. The properties of this material were compared with those of the LDH and CLDH submitted to adsorption tests. For this synthesis, a solution containing $\mathrm{Mg}\left(\mathrm{NO}_{3}\right)_{2} \cdot 6 \mathrm{H}_{2} \mathrm{O}(5.40 \mathrm{mmol})$ and $\mathrm{Al}\left(\mathrm{NO}_{3}\right)_{3} \cdot 9 \mathrm{H}_{2} \mathrm{O}$ $(1.80 \mathrm{mmol})$ in water $(25.0 \mathrm{~mL})$ was added dropwise under vigorous stirring to a solution containing AY $(4.50 \mathrm{mmol})$ in water $(100 \mathrm{~mL})$. The resulting slurry was washed with deionized water by centrifugation/resuspension cycles until the $\mathrm{pH}$ value was 7 . The solid material obtained was hydrothermally treated at $65^{\circ} \mathrm{C}$ for $24 \mathrm{~h}$. The material was then dried at reduced pressure in the presence of silica gel.

\subsection{Characterization methods}

The elemental analysis was carried out using a ContrAA 300 highresolution continuum source flame atomic absorption spectrometer (Analytik Jena). X-ray diffraction (XRD) was performed using a Shimadzu XRD-6000 diffractometer with graphite crystal as monochromator to select $\mathrm{Cu}-\mathrm{K} \alpha_{1}$ radiation $(\lambda=1.5406 \AA)$, with a scanning rate of $0.02^{\circ} \cdot \mathrm{s}^{-1}$. Thermogravimetric analyses (TGA) were carried out under synthetic air atmosphere at $10^{\circ} \mathrm{C} \cdot \mathrm{min}^{-1}$, using TGA/DSC 490 PC Luxx. Attenuated Total Reflectance with Fourier Infrared Spectroscopy (ATR-FTIR) spectra were recorded on a Jasco FTIR 4100 spectrophotometer. The specific surface area and pore distribution of the material were analyzed by $\mathrm{N}_{2}$ adsorption-desorption isotherms at $-196{ }^{\circ} \mathrm{C}$ on a Micromeritics ASAP 2000 instrument. SEM analysis was accomplished on a scanning electron microscope provided with a field emission gun (FEG-SEM, JEOL-7500F). The samples were supported in the sample chamber by dispersing the powder upon conductive double-sided carbon tape.

\subsection{Batch adsorption tests}

\subsubsection{Analysis of the azo dye concentration}

The concentration of AY in the supernatant - determined eventually by comparison with a previously obtained standard curve - was obtained using a UV-vis spectrophotometer (Evolution 300, Thermo) with the absorbance being measured at $\lambda=410 \mathrm{~nm}$ in quartz cuvettes with an optical path length of $10 \mathrm{~mm}$.

\subsubsection{Effect of initial $\mathrm{pH}$ value}

As the dye adsorption capacity of the CLDH was much greater than that of $\mathrm{LDH}$, the effect of $\mathrm{pH}$ value, temperature and the adsorption kinetics were studied only for CLDH. Suspensions were stirred in a thermostatic bath at $25^{\circ} \mathrm{C}$ for $420 \mathrm{~min}$. The tested initial $\mathrm{pH}$ values - adjusted by $\mathrm{NaOH}$ or $\mathrm{HCl}$ solution addition - were 4.0, 7.0, and 12.0. The dye concentration of these solutions ranged from 50 to $2000 \mathrm{mg} \cdot \mathrm{L}^{-1}$.

\subsubsection{Adsorption kinetics}

The suspensions were prepared by adding CLDH (10 mg) to $20 \mathrm{~mL}$ AY solutions $\left(250,500,1000\right.$ and $\left.2000 \mathrm{mg} \cdot \mathrm{L}^{-1}\right)$ at a $\mathrm{pH}$ of 7.0 . The suspensions were placed in a thermostatic bath at $25^{\circ} \mathrm{C}$ under stirring for different times (0-420 $\mathrm{min}$ ) and the solid material was then separated by centrifugation. The kinetic models of pseudo-first order (Eq. (1)), pseudo-second order (Eq. (2)) and intraparticle diffusion (Eq. (3)) were tested.

$$
\begin{aligned}
& \log \left(\mathrm{q}_{\mathrm{e}}-\mathrm{q}_{\mathrm{t}}\right)=\log \mathrm{q}_{\mathrm{e}}-\frac{\mathrm{k}_{1}}{2.303} \mathrm{t} \\
& \frac{\mathrm{t}}{\mathrm{q}_{\mathrm{t}}}=\frac{1}{\mathrm{k}_{2} \mathrm{q}^{2}}+\frac{1}{\mathrm{q}_{\mathrm{e}}} \mathrm{t} \\
& \mathrm{q}_{\mathrm{t}}=\mathrm{k}_{\mathrm{i}} \mathrm{t}^{1 / 2}+\mathrm{C}
\end{aligned}
$$

where $\mathrm{q}_{\mathrm{e}}$ and $\mathrm{q}_{\mathrm{t}}$ are the adsorbed amounts $\left(\mathrm{mg} \cdot \mathrm{g}^{-1}\right.$ ) of AY per gram of adsorbent at equilibrium and at time $\mathrm{t}\left(\mathrm{min}\right.$ ), respectively; $\mathrm{k}_{1}$ and $\mathrm{k}_{2}$ are the velocity constants of pseudo first-order and pseudo second-order, respectively; $\mathrm{k}_{\mathrm{i}}$ is the constant representing the intraparticle diffusion rate, and $\mathrm{C}$ is the intercept.

\subsubsection{Adsorption isotherms and thermodynamic study}

Adsorption isotherms were determined from the adsorption equilibrium of the kinetic experiments (420 min). The dye concentration of these solutions ranged from 50 to $2000 \mathrm{mg} \cdot \mathrm{L}^{-1}$. The suspensions were stirred in a thermostatic reciprocating shaking bath at 25, 30, 35 and $40{ }^{\circ} \mathrm{C}$. The amount of AY adsorbed at equilibrium $\left(\mathrm{q}_{\mathrm{e}}, \mathrm{mg} \cdot \mathrm{g}^{-1}\right)$ was calculated using the following equation:

$\mathrm{q}_{\mathrm{e}}=V \cdot \frac{\left(C_{0}-C_{e}\right)}{m}$

where $C_{0}$ is the initial dye concentration $\left(\mathrm{mg} \cdot \mathrm{L}^{-1}\right) ; C_{e}$ is the equilibrium dye concentration $\left(\mathrm{mg} \cdot \mathrm{L}^{-1}\right) ; V$ is the volume (L) of the dye solution; and $m$ is the mass $(\mathrm{g})$ of LDH or CLDH. 


\subsubsection{Recyclability of the adsorbent}

The recyclability of the adsorbent was evaluated by repeated adsorption/calcination cycles using the same CLDH sample. A constant dosage of CLDH ( $500 \mathrm{mg} \cdot \mathrm{L}^{-1}$ ) was placed in $250 \mathrm{mg} \cdot \mathrm{L}^{-1} \mathrm{AY}$ solutions at $25^{\circ} \mathrm{C}$ and kept in contact for $420 \mathrm{~min}$. This procedure was repeated five times, with the adsorption capacity being calculated for each cycle.

\section{Results and discussion}

\subsection{Materials characteristics}

According to the elemental analysis and TGA curve, the molar Mg:Al ratio was equal to 2.70 and the water amount was $14.3 \%$, respectively, corresponding to the $\mathrm{LDH}$ formula $\left[\mathrm{Mg}_{0.73} \mathrm{Al}_{0.27}(\mathrm{OH})_{2}\right]\left(\mathrm{CO}_{3}\right)_{0.13} \cdot 0.62$ $\mathrm{H}_{2} \mathrm{O}$. Considering that $A Y^{2-}$ dye can be immobilized on $\mathrm{LDH}$ by ion exchange reaction, its expected AY dye adsorption capacity is $1.724 \mathrm{mmol} \cdot \mathrm{g}^{-1}$. Nevertheless, it is well known that the carbonate anions are not easily exchanged by other anions. In this context, the adsorption studies will be focused on CLDH, due to the carbonate decomposition during the calcination. The mixed oxide put in contact with an anionic solution, is rehydrated, recovering the LDH structure, allowing the intercalation of anions to balance the positive charged LDH layers.

The XRD patterns (Fig. 1) of the materials $\mathrm{LDH}, \mathrm{CLDH}$, RLDH (sample obtained after CLDH contact with a $2000 \mathrm{mg} \cdot \mathrm{L}^{-1} \mathrm{AY}$ solution at $\mathrm{pH}$ value 7.0 for 420 min at $25{ }^{\circ} \mathrm{C}$ ) and LDH-AY were recorded. For the LDH sample, basal reflections, which are related to the lamellar stacking plane characteristic of LDH structure, can be observed for ( $00 l)$ planes, where $l=3,6$ and 9 (Fig. 1a.). For this material, the interlayer space (d) calculated from the Bragg equation $(\mathrm{n} \lambda=2 \mathrm{~d} \cdot \operatorname{sen} \theta)$ is $7.65 \AA$, which can be assigned to the intercalation of carbonate ions between the inorganic lamellae (Forano et al., 2013). For CLDH, the XRD analysis (Fig. 1b) showed a collapse of the layered structure, evidenced by the disappearance of the basal reflections, and the typical formation of the defect periclase $\mathrm{MgO}$ structure $(\mathrm{Mg}(\mathrm{Al}) \mathrm{O})$, (Thomas et al., 2006). The diffractogram of RLDH (Fig. 1c) indicates the presence of two LDH phases. One phase is related to the intercalation of AY, labeled as squares in Fig. 1 , with $\mathrm{d}_{003}$ equal to 20.0 A. The other phase with $\mathrm{d}_{003}$ equal to $7.54 \AA$, labeled as triangles in Fig. 1, is attributed to the

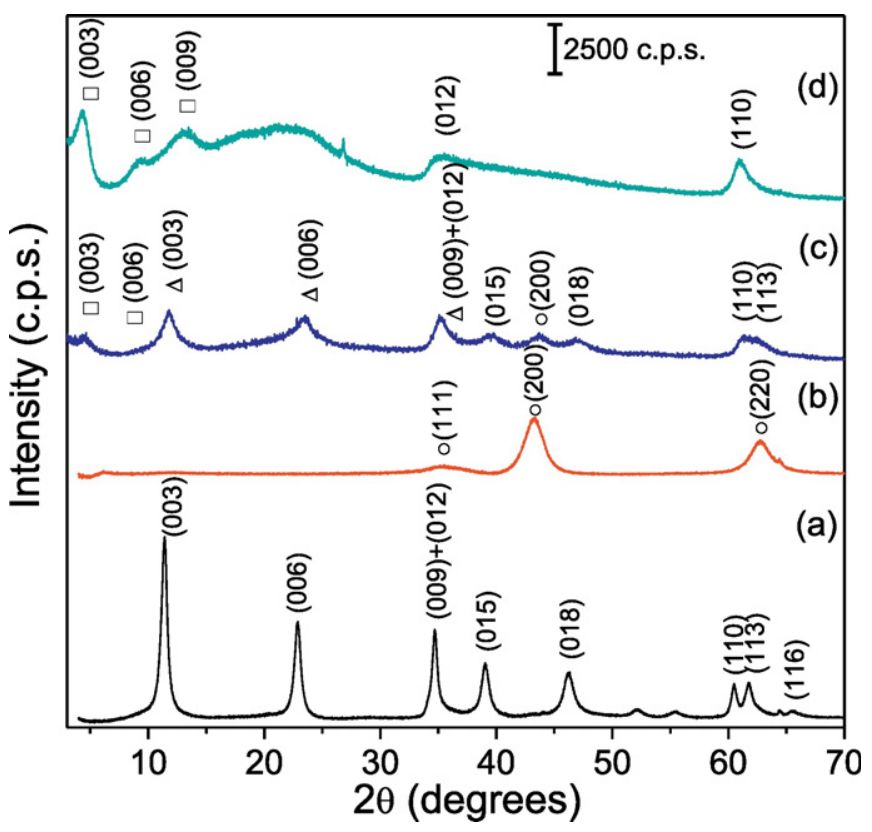

Fig. 1. XRD patterns of (a) LDH, (b) CLDH, (c) RLDH and (d) LDH-AY. $\Delta=L D H ; O=$ periclase MgO phase (ICSD no. 95468), $\square=$ LDH-AY phase. intercalation of hydroxide and/or carbonate ions. The recovery of the lamellar structure after the adsorption experiments is related to a property known as the "memory effect" (Forano et al., 2013; Baskaran et al., 2015). The diffractogram of LDH-AY (reported here for the first time) (Fig. 1d.) shows the presence of basal reflections (003), (006) and (009) and an interlamelar space value equal to $20.2 \AA$. This value is very close to that one observed for RLDH, which indicates an intercalation process of the AY when using CLDH.

The ATR-FTIR spectrum of LDH (Fig. 2a) shows characteristic bands of hydrotalcite-type compounds. The bands at 3440 and $1640 \mathrm{~cm}^{-1}$ are attributed respectively to the $\mathrm{O}-\mathrm{H}$ stretching and bending vibrations of hydroxyl groups and water molecules (Benselka-Hadj Abdelkader et al., 2011). The band at $1364 \mathrm{~cm}^{-1}$ is assigned to a vibrational mode of the $\mathrm{CO}_{3}^{2-}$ anions (Roelofs et al., 2002; Li et al., 2016). The ATR-FTIR spectrum of CLDH (Fig. 2b) shows bands in the region below $850 \mathrm{~cm}^{-1}$, which are assigned to the vibrational modes of $\mathrm{Al}-\mathrm{O}$ and $\mathrm{Mg}-\mathrm{O}$ in the $\mathrm{Mg}(\mathrm{Al}) \mathrm{O}$ resultant material (Auxilio et al., 2009; Santos et al., 2013). The ATR-FTIR spectrum of RLDH (Fig. 2c) displays several bands characteristic of the organic dye (Fig. 2d), and the existence of a band at $1650 \mathrm{~cm}^{-1}$ attests that the CLDH sample was rehydrated. In the RLDH spectrum, the bands corresponding to the antisymmetric vibrational modes of the sulfonate groups of AY are observed at 1367 and $1337 \mathrm{~cm}^{-1}$, and the symmetric vibrations at 1024 and $997 \mathrm{~cm}^{-1}$. Bands at $2910 \mathrm{~cm}^{-1}$ and $1461 \mathrm{~cm}^{-1}$ are also observed, which are related to the axial deformation and bending of the $\mathrm{C}-\mathrm{H}$ of the $\mathrm{CH}_{3}$ in the dye structure respectively, while the bands at $1148 \mathrm{~cm}^{-1}$ and $1157 \mathrm{~cm}^{-1}$ are related to the $\mathrm{C}-\mathrm{N}$ vibration (Extremera et al., 2012). The bands at $1600-1400 \mathrm{~cm}^{-1}$ and $800-700 \mathrm{~cm}^{-1}$ regions are attributed to the aromatic ring stretching and bending, respectively. These bands confirm that the AY molecules adsorbed into the material, thus keeping their original structure.

The TGA curve of LDH (Fig. 3a) shows the usual thermal decomposition profile of these materials (Forano et al., 2013). The events can be divided into three main steps: the first one occurs between room temperature and $210{ }^{\circ} \mathrm{C}$ (mass loss of about 14\%) and corresponds to the evaporation of weakly adsorbed water molecules on the surface, as well as water molecules from the interlayer space. The second event, which ranges from $210{ }^{\circ} \mathrm{C}$ to $450{ }^{\circ} \mathrm{C}$ (mass loss of $18 \%$ ), is related to the decomposition of the hydroxide layers. The third step has an overlap with the second one (mass loss of 3\%), and is ascribed to the decomposition of $\mathrm{CO}_{3}^{2-}$ anions from the interlamellar space, leading to the collapse of the layered structure concomitantly with the oxide crystallization (Constantino and Pinnavaia, 1995). TGA curve of RLDH sample (Fig. 3b) also presents events that can be divided into three main steps. The first one occurs from room temperature to $218{ }^{\circ} \mathrm{C}$ (mass

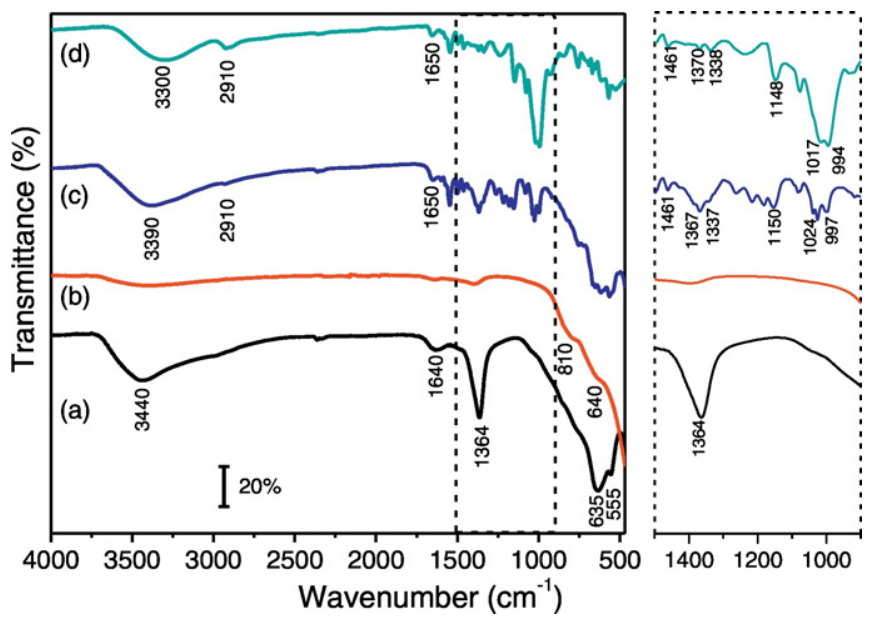

Fig. 2. FTIR spectra of (a) LDH, (b) CLDH, (c) RLDH and (d) AY. 
(a)

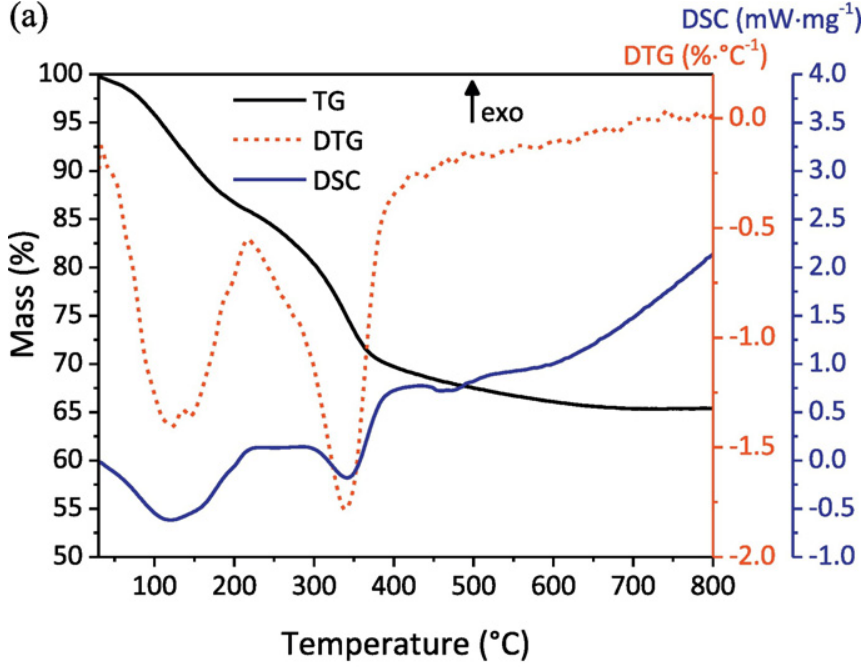

(b)

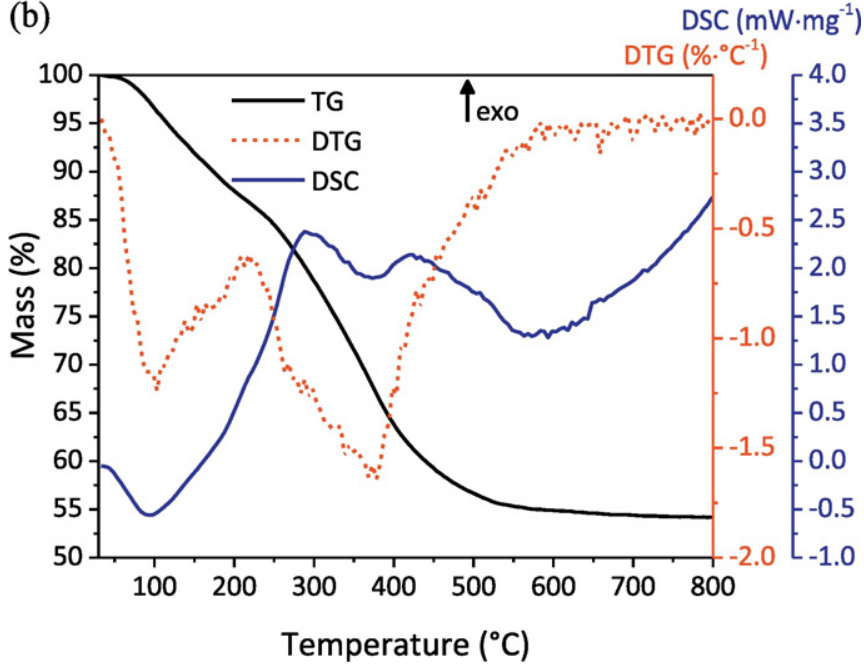

Fig. 3. Simultaneous TG, DTG and DSC analysis profiles for (a) LDH and (b) RLDH samples.

loss of $14 \%$ ) and it is related to the material dehydration. The second step is observed from $218{ }^{\circ} \mathrm{C}$ to $580{ }^{\circ} \mathrm{C}$ (mass loss of 31\%) and it is assigned to the occurrence of concomitant events: (i) the release of water molecules from dehydroxylation process of the LDH layers; (ii) the decomposition of the adsorbed and intercalated AY anions. In the second step of decomposition, DSC curve presents one overlap of two exothermic processes associated to the release of $\mathrm{CO}_{2}$ from adsorbed and intercalated $\mathrm{AY}$ anions. The third step occurs at temperatures above $580{ }^{\circ} \mathrm{C}$ and the small weight loss of about $1 \%$ can be associated to release of $\mathrm{CO}_{2}$ derived of reminiscent $\mathrm{AY}$ anions. Based on the residue mass of the two samples, RLDH has more volatile products than $\mathrm{LDH}$, corroborating with the proposal of AY adsorption/intercalation into the inorganic adsorbent, as already suggested by XRD and vibrational spectroscopy data.

$\mathrm{N}_{2}$ adsorption/desorption isotherms of LDH and CLDH are shown in Fig. 4. According to the IUPAC classification, the LDH and CLDH samples displayed the II-type adsorption isotherm characterized by the absence of a plateau in the relative pressure close to 1 , evidencing the presence of macroporous, i.e. pore sizes larger than $50 \mathrm{~nm}$. However, the hysteresis loop between the adsorption and desorption branches is characteristic of mesoporous materials with pore sizes smaller than $50 \mathrm{~nm}$. Therefore, the presence of both features hints on the coexistence of mesopores and macropores. The shape of the hysteresis loop is in accordance with the H3 type of IUPAC classification, usually associated to slitshaped pores formed by platelet aggregation resulting in large pores size distribution. The inset information in Fig. 4 shows a wide range of

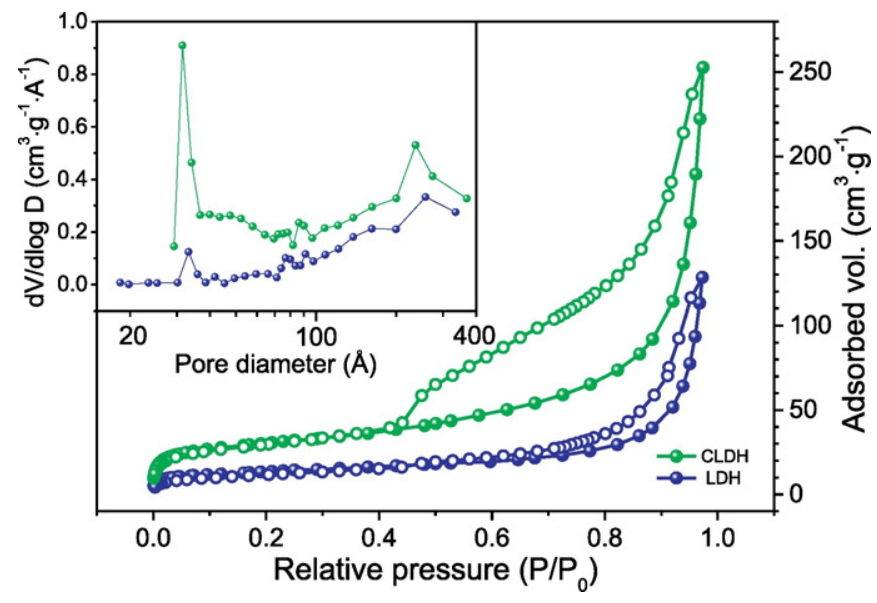

Fig. 4. $\mathrm{N}_{2}$ adsorption/desorption isotherms of the LDH and CLDH samples. Inset shows the pore size distribution of the materials.

pore size distribution for both materials, but a large increase in the frequency of mesopores with size lower than $70 \AA$ is verified after LDH calcination. This result was expected due to the release of water and carbonate from the structure (the latter as carbon dioxide), giving rise to a new mesopores family. This inherent mesoporosity, makes the CLDH material appropriate for adsorption processes involving species with dimensions between 5 and $20 \AA$ (Auxilio et al., 2009).

The textural properties of the materials are reported in Table 1. The mean mesopore size was determined by the ratio between the mesopore volume $\left(\mathrm{V}_{\mathrm{mp}}\right)$ and the specific surface area $\left(\mathrm{S}_{\mathrm{BET}}\right), 4 \mathrm{~V}_{\mathrm{mp}} /$ $\mathrm{S}_{\mathrm{BET}}$, encompassing the different pore shapes and families. The analysis of the specific surface area and mesopore volume shows that the calcined material performs twice as well as the precursor material, while the mean mesopore size decreased to a half. These features evidence that LDH calcination lead the formation of small mesoporous due to the emptying of the interlamellar space induced by the release of the intercalated species. On opposite the specific surface area and pore volume of RLDH considerably decreased (7.5 and 9.5 times, respectively), while the mean mesopore size increased, due recovery of the lamellar structure during the AY adsorption.

The SEM images of LDH and CLDH (Fig. 5a and b) presented platelets arrayed in a rosette aggregate crystal shape. In the case of CLDH (Fig. 5b), the collapse of the LDH structure, due to the calcination process, produces a rearrangement of the platelets. The SEM images of RLDH (Fig. 5c) suggest the coating of platelets by AY anions, resulting in a structure with defects and interconnected edges.

\subsection{Batch adsorption tests}

\subsubsection{Effect of initial $\mathrm{pH}$ value}

The effect of solution $\mathrm{pH}$ value on the removal of AY by CLDH was studied and adsorption isotherms at $25{ }^{\circ} \mathrm{C}$ are displayed in Fig. 6. When the $\mathrm{pH}$ of the initial solution was 4.0, the efficiency of dye removal by CLDH was lower than at $\mathrm{pH}$ 7.0. This can be explained by the increased solubility of CLDH in an acidic medium. At $\mathrm{pH}$ value 12.0 , the

Table 1

Experimental textural properties of the samples.

\begin{tabular}{llll}
\hline Sample & $\begin{array}{l}\text { Surface area } \\
\left(\mathrm{m}^{2} \cdot \mathrm{g}^{-1}\right)\end{array}$ & $\begin{array}{l}\text { Average pore diameter } \\
(\AA)\end{array}$ & $\begin{array}{l}\text { Pore volume }^{\mathrm{b}} \\
\left(\mathrm{cm}^{3} \cdot \mathrm{g}^{-1}\right)\end{array}$ \\
\hline LDH & 48 & 144 & 0.175 \\
CLDH & 105 & 80 & 0.361 \\
RLDH & 14 & 99 & 0.038 \\
\hline
\end{tabular}

\footnotetext{
a BET method.
}

b BJH method. 

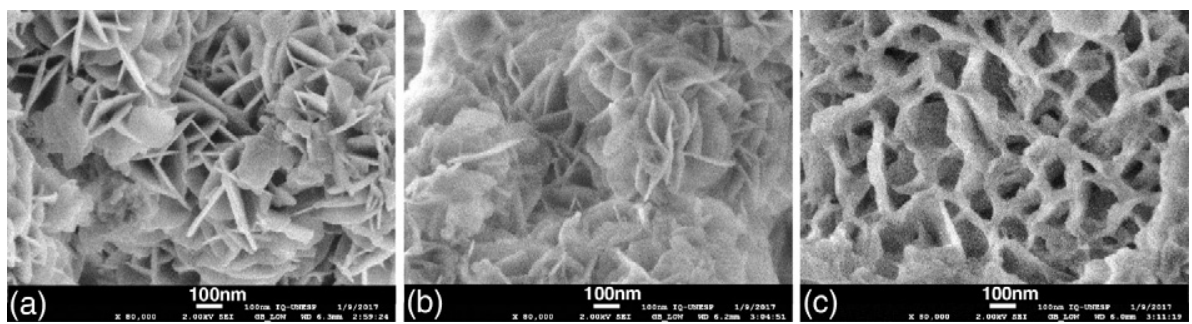

Fig. 5. SEM micrograph of (a) LDH (b) CLDH, and (c) RLDH.

isotherm shows a lower efficiency of dye adsorption than at pH 4.0 and 7.0 due to the decrease in positive charge density on the surface of CLDH - neutralized by the excess $\mathrm{OH}^{-}$ions present in the medium. The isoelectric point of $\mathrm{Mg}-\mathrm{Al}-\mathrm{CO}_{3}-\mathrm{LDH}$ is 10 and its zeta potential at $\mathrm{pH} 12$ is $-30 \mathrm{mV}$, i.e., the LDH surface is very negatively charged above $\mathrm{pH} 10$ (Pavan et al., 1999). The efficiency of AY adsorption was highest at $\mathrm{pH}$ value 7.0, which means that this type of adsorbent material is more attractive for anionic dye adsorption in aqueous neutral solutions. The LDH has a positive zeta potential at $\mathrm{pH} 7.0$ and the dye is negatively charged, therefore electrostatic interactions are favored.

\subsubsection{Kinetics of $A Y$ adsorption onto $C L D H$}

The kinetic study for LDH was not included in this work due to the lower adsorption capacity for this material compared to CLDH. The effect of the initial concentration of AY dye solution on the kinetics of AY adsorption onto CLDH was verified (Fig. 7). The amount of adsorbed AY increased rapidly in the first hour and reached steady state equilibrium after about $5 \mathrm{~h}$.

The experimental data were best fitted using a pseudo-second-order equation (Fig. 7a dashed lines), showing that the process is controlled by chemical adsorption. The kinetic parameters for the adsorption of AY onto CLDH were calculated (Table. 2).

The intraparticle diffusion model (Fig. 7b) provides a possible mechanism by which the adsorption occurs as a function of contact time. Since the adsorbent material has a textured porous structure, the adsorption process can occur in a complex way and at different stages, such as external mass transfer, inner diffusion of the adsorbate into the pores, and adsorption onto actives sites. For sample in contact with 1000 and $2000 \mathrm{mg} \cdot \mathrm{L}^{-1}$ AY solutions the plots of the intraparticle diffusion model show three main region shapes, which are attributed

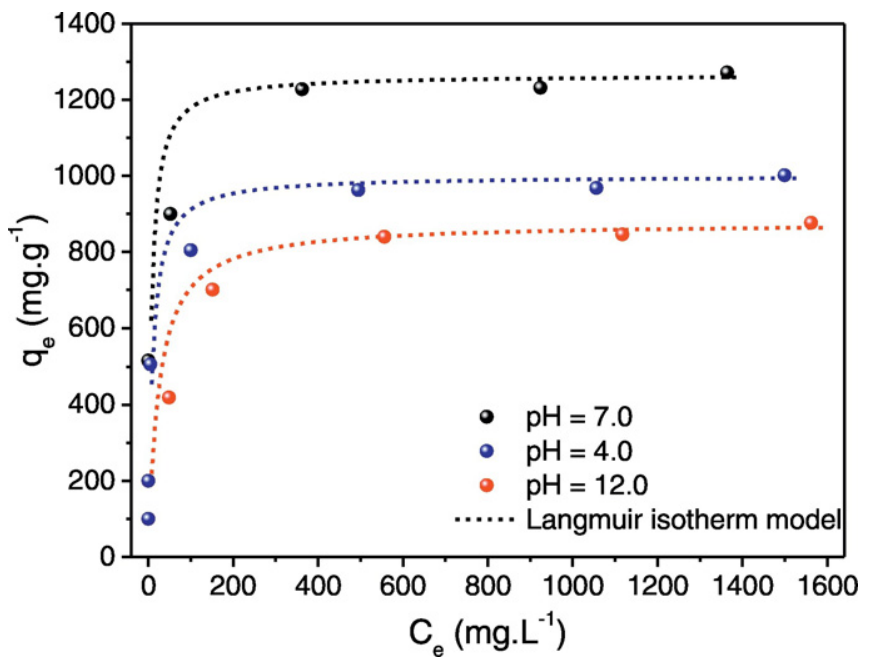

Fig. 6. Kinetics of AY adsorption on CLDH at different initial concentration and data fitting by (a) pseudo second-order kinetic model and (b) intraparticle diffusion model ( $\mathrm{T}=$ $\left.25^{\circ} \mathrm{C} ; \mathrm{C}_{0}=500 \mathrm{mg} \cdot \mathrm{L}^{-1} \mathrm{CLDH} ; \mathrm{pH}=7.0\right)$. to external surface instantaneous adsorption $\left(\mathrm{k}_{\mathrm{D} 1}\right)$, gradual intraparticle diffusion $\left(\mathrm{k}_{\mathrm{D} 2}\right)$ and the final equilibrium stage $\left(\mathrm{k}_{\mathrm{D} 3}\right)$, where the availability of active sites decreases and the intraparticle diffusion slows down (Zhang et al., 2014). The first step shows a higher adsorption rate in the first hour. The second step is related to the rate-determining step in which the process occurs by intraparticle diffusion. The last step also occurs as a rate-determining step but as a consequence of the thermodynamic equilibrium reached with the gradual saturation of the adsorption sites. For the less concentrated AY solutions (500 and $250 \mathrm{mg} \cdot \mathrm{L}^{-1}$ ), the profile of adsorption process is characterized by a single step, during the first $2 \mathrm{~h}$, followed by a plateau. This feature indicates that the adsorption occurs mainly on the external surface for solutions with low AY concentration.
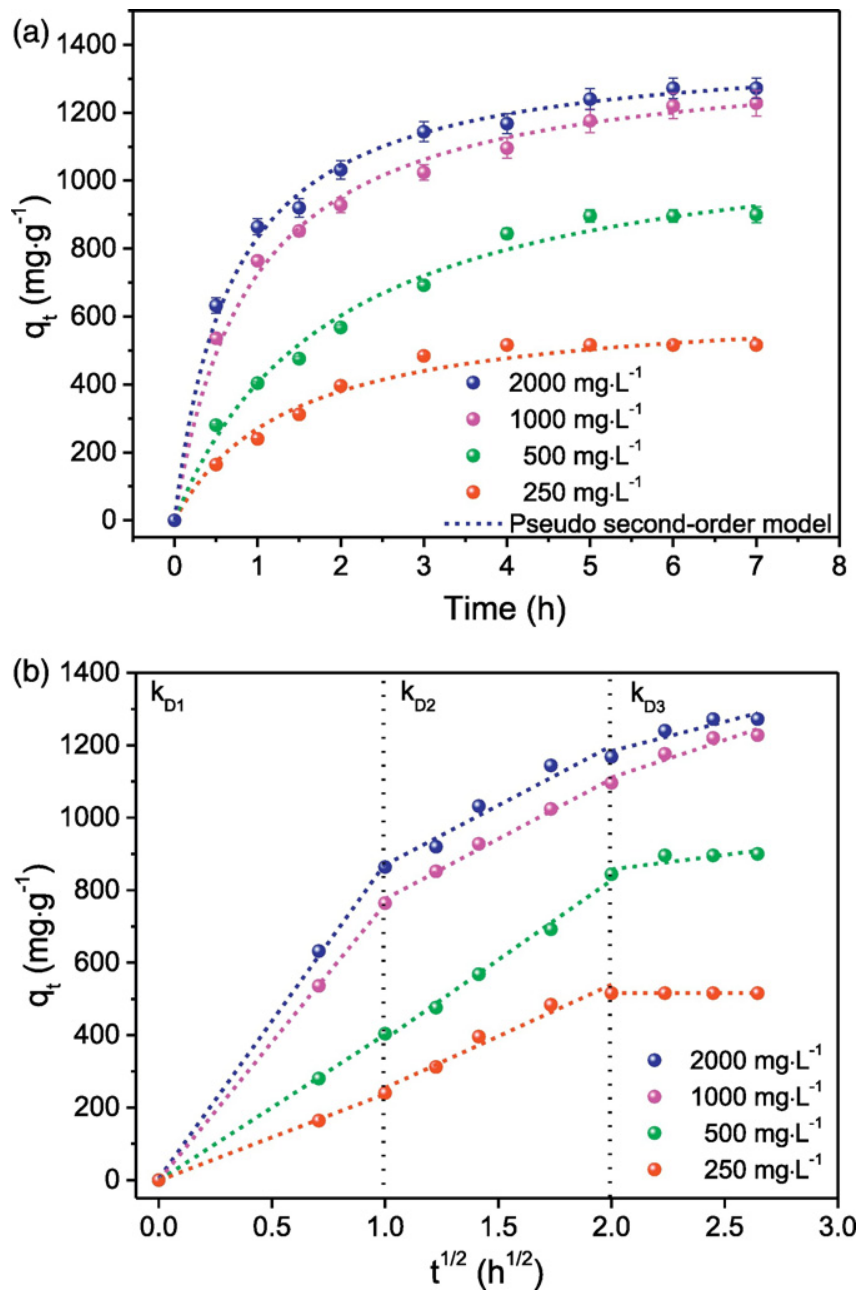

Fig. 7. Adsorption isotherms of AY onto CLDH at different temperatures. Inset shows the adsorption isotherm using uncalcined $\mathrm{LDH}$ at $25{ }^{\circ} \mathrm{C}$ 
Table 2

Pseudo second-order parameters for the adsorption kinetics of AY on CLDH.

\begin{tabular}{llll}
\hline$C_{0}\left(\mathrm{mg} \cdot \mathrm{L}^{-1}\right)$ & $\mathrm{k}_{2}\left(\mathrm{~g} \cdot \mathrm{mg}^{-1} \cdot \mathrm{h}^{-1}\right)$ & $\mathrm{q}_{\mathrm{e}}\left(\mathrm{mg} \cdot \mathrm{g}^{-1}\right)$ & $\mathrm{R}_{2}^{2}$ \\
\hline 250 & $1.14 \cdot 10^{-3}$ & 641.0 & 0.984 \\
500 & $4.45 \cdot 10^{-4}$ & 1178 & 0.985 \\
1000 & $8.00 \cdot 10^{-4}$ & 1382 & 0.998 \\
2000 & $1.05 \cdot 10^{-3}$ & 1399 & 0.999 \\
\hline
\end{tabular}

\subsubsection{Adsorption isotherms}

As stated above, batch experiments were used to interpret the adsorption equilibrium. In this study, the experimental data were analyzed according to the Langmuir and Freundlich isotherm models presented in the Supplementary information. The adsorption capacity of LDH and CLDH samples (Fig. 8) increased gradually when the dye concentration in the aqueous phase increased, reaching saturation at high concentrations.

The equation for the line of best fit obtained for the Langmuir model showed a greater correlation coefficient $\left(R_{L}^{2}\right)$ than for the Freundlich model $\left(R_{F}^{2}\right)$ (Table 3), indicating homogeneity of the surface of the adsorbent material and the formation of a monolayer of azo dye species covering the surface of the adsorbent.

The adsorption capacity of CLDH was almost four times greater $\left(1266 \mathrm{mg} \cdot \mathrm{g}^{-1}\right.$ or $1.669 \mathrm{mmol} \cdot \mathrm{g}^{-1}$ ) than that of the precursor LDH (330.0 $\mathrm{mg} \cdot \mathrm{g}^{-1}$ or $0.4350 \mathrm{mmol} \cdot \mathrm{g}^{-1}$ ), demonstrating a higher affinity between the adsorbent and the adsorbate. The high adsorption capacity of the CLDH is due to the recovery process (intercalation and adsorption), its greater specific surface area and its positive charged sites (Guo et al., 2013). Considering the specific surface area of both CLDH and LDH materials, the adsorption capacities could be expressed respectively as 12.06 and $6.875 \mathrm{mg} \cdot \mathrm{m}^{-2}$, showing that the calcined material has almost twice of available adsorption sites per $\mathrm{m}^{2}$ than the pristine $\mathrm{LDH}$. Taking the CLDH formula and considering that all carbonate anions are lost in calcination (and all LDH is recovered), the expected adsorption capacity was $3.125 \mathrm{mmol} \cdot \mathrm{g}^{-1}$, by the following reaction with AY anions (Extremera et al., 2012):

$$
\begin{aligned}
& \mathrm{Mg}_{0.73} \mathrm{Al}_{0.27} \mathrm{O}_{1.135}+0.135 \mathrm{AY}^{2-} \\
& \quad+(\mathrm{m}+1.135) \mathrm{H}_{2} \mathrm{O} \rightarrow\left[\mathrm{Mg}_{0.73} \mathrm{Al}_{0.27}(\mathrm{OH})_{2}\right] \mathrm{AY}_{0.135} \cdot \mathrm{mH}_{2} \mathrm{O} \\
& \quad+0.27 \mathrm{OH}^{-}
\end{aligned}
$$

In this case, the recovery of the LDH structure occurs by the adsorption process, where the AY ions are neutralizing the positive electrical charge of the layers. The experimental adsorption capacity of $1.669 \mathrm{mmol} \cdot \mathrm{g}^{-1}$ is half of the expected capacity $\left(3.125 \mathrm{mmol} \cdot \mathrm{g}^{-1}\right)$

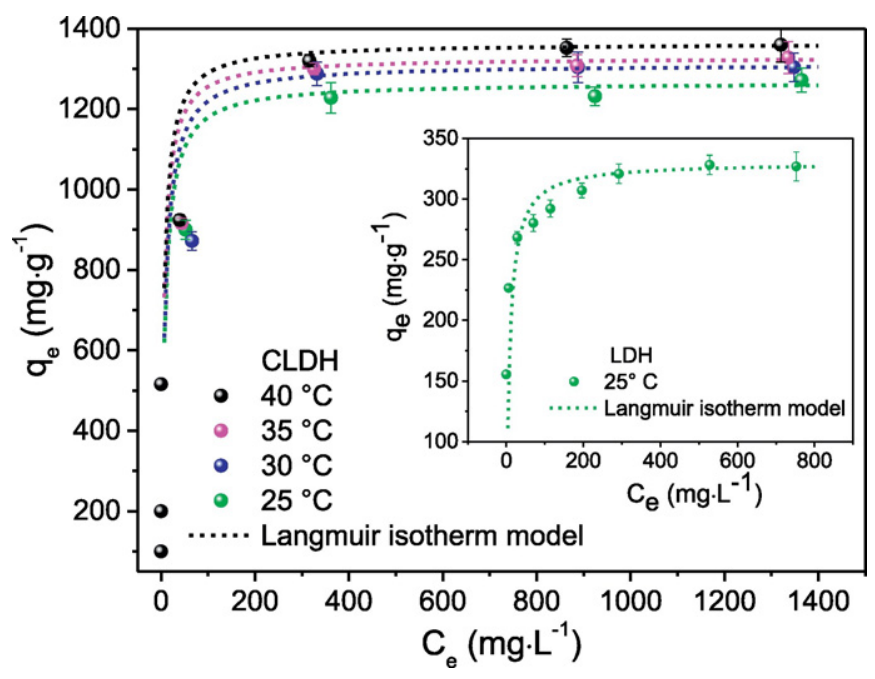

Fig. 8. Effect of $\mathrm{pH}$ on the AY adsorption onto $\mathrm{CLDH}$ at $25^{\circ} \mathrm{C}$.

\begin{tabular}{|c|c|c|c|c|c|c|c|}
\hline \multirow[t]{2}{*}{ Adsorbent } & \multirow[t]{2}{*}{$\begin{array}{l}\text { Temperature } \\
\left({ }^{\circ} \mathrm{C}\right)\end{array}$} & \multicolumn{3}{|c|}{ Langmuir constants } & \multicolumn{3}{|c|}{$\begin{array}{l}\text { Freundlich } \\
\text { constants }\end{array}$} \\
\hline & & $\begin{array}{l}\mathrm{q}_{\max } \\
\left(\mathrm{mg} \cdot \mathrm{g}^{-1}\right)\end{array}$ & $\begin{array}{l}k_{L} \\
\left(\mathrm{~L} \cdot \mathrm{mg}^{-1}\right)\end{array}$ & $\mathrm{R}_{\mathrm{L}}^{2 \mathrm{a}}$ & $k_{F}$ & $N$ & $\mathrm{R}_{\mathrm{F}}^{2 \mathrm{a}}$ \\
\hline LDH & 25 & 330.0 & 0.1264 & 0.999 & 201.0 & 12.7 & 0.937 \\
\hline CLDH & 25 & 1266 & 0.1364 & 0.999 & 609.8 & 9.45 & 0.851 \\
\hline CLDH & 30 & 1312 & 0.1323 & 0.999 & 522.1 & 7.39 & 0.744 \\
\hline $\mathrm{CLDH}$ & 35 & 1328 & 0.1747 & 0.999 & 624.9 & 9.03 & 0.818 \\
\hline CLDH & 40 & 1363 & 0.1763 & 0.999 & 628.1 & 8.77 & 0.846 \\
\hline
\end{tabular}

Table 3

Langmuir and Freundlich parameters for the adsorption of AY on LDH and CLDH.

${ }^{a} \mathrm{R}_{\mathrm{L}}^{2}$ and $\mathrm{R}_{\mathrm{F}}^{2}$ : correlation coefficients of Langmuir and Freundlich, respectively.

due the incomplete LDH recovery and the formation of the carbonateor hydroxide-intercalated LDH phase, as suggested by XRD and vibrational spectroscopy data. Similar findings were reported in the literature for calcined Mg-Al-CO 3 LDH (Auxilio et al., 2009; Santos et al., 2013). Some $\mathrm{q}_{\max }$ values reported in the literature for dye adsorption/sorption on CLDH are gathered in Table 4. The results highlight the higher performance obtained in this work in comparison with the cited studies for dyes applied in various dyeing processes.

\subsubsection{Thermodynamic study}

The effect of temperature on AY adsorption by CLDH was investigated using the adsorption isotherms at each temperature (Fig. 8). The amount of AY adsorbed on CLDH improved with increasing temperature, which are expected for endothermic process. The thermodynamic adsorption properties $\Delta H, \Delta S$ and $\Delta G$ were calculated using Eqs. (5) and (6) (Van't Hoff equation):

$\Delta G^{\circ}=-R T \ln k_{a d}$

$\ln k_{a d}=-\Delta H^{\circ} / R T+\Delta S^{\circ} / R$

where $k_{a d}$ is the Langmuir constant $\left(\mathrm{L} \cdot \mathrm{mg}^{-1}\right)$ - obtained in each adsorption isotherm - multiplied by the density of water $\left(10^{6} \mathrm{mg} \cdot \mathrm{L}^{-1}\right)$ (Yu et al., 2015). The extensive thermodynamic properties can be evaluated from the Van't Hoff plot shown in Supplementary information (Fig. S1), and the results are reported in Table 5.

The positive value of enthalpy $\left(\Delta H^{\circ}\right)$ confirms the endothermic nature of the process, while the positive value of entropy $\left(\Delta S^{\circ}\right)$ suggests an increase in disorder at the solid-solution interface. The negative values for Gibbs free energy $\left(\Delta G^{\circ}\right)$ indicate that the adsorbed dye is more stable than when in solution. Similar results for increased adsorption capacity at higher temperatures are reported in the literature for different CLDH of $\mathrm{Zn}-\mathrm{Al}, \mathrm{Mg}-\mathrm{Al}, \mathrm{Mg}$ - Fe (Ni et al., 2007; Asouhidou et al., 2012; Extremera et al., 2012).

\begin{tabular}{|c|c|c|c|}
\hline $\begin{array}{l}\mathrm{Mg}: \mathrm{Al} \text { molar } \\
\text { ratio }\end{array}$ & Dye & $\begin{array}{l}\mathrm{q}_{\max } \\
\left(\mathrm{mg} \cdot \mathrm{g}^{-1}\right)\end{array}$ & Reference \\
\hline $3: 1$ & Acid orange 10 & 227.089 & $\begin{array}{l}\text { Extremera et al. } \\
\text { (2012) }\end{array}$ \\
\hline $2: 1$ & Remazol orange GR110 & 106.27 & Teixeira et al. (2012) \\
\hline $2: 1$ & $\begin{array}{l}\text { Remazol golden yellow } \\
\text { RNL }\end{array}$ & 657.2 & Teixeira et al. (2012) \\
\hline $3: 1$ & Acid orange 10 & 134.37 & $\begin{array}{l}\text { Asouhidou et al. } \\
(2012))\end{array}$ \\
\hline $2: 1$ & Methyl orange & 577.5 & Zheng et al. (2012) \\
\hline $3: 1$ & Acid green 68:1 & 154.8 & Santos et al. (2013) \\
\hline $2: 1$ & Brilliant blue R (BBR) & 620 & Zhu et al. (2005) \\
\hline $2: 1$ & Benzopurpurine 4B & 417.36 & $\begin{array}{l}\text { Drici Setti et al. } \\
(2010)\end{array}$ \\
\hline $1: 1$ & Congo red & 143.27 & Li et al. (2016) \\
\hline $2: 1$ & Methyl orange & 1219.5 & Deng et al. (2016) \\
\hline $3: 1$ & Acid Yellow 42 & 1265.9 & This study \\
\hline
\end{tabular}

Table 4

Comparison of several $\mathrm{q}_{\max }$ values reported for dye adsorption/sorption on CLDH. 
Table 5

Thermodynamic parameters at various temperatures.

\begin{tabular}{llll}
\hline Temperature $\left({ }^{\circ} \mathrm{C}\right)$ & \multicolumn{3}{l}{ Thermodynamic parameters } \\
\cline { 2 - 4 } & $\Delta G\left(\mathrm{~kJ} \cdot \mathrm{mol}^{-1}\right)$ & $\Delta H\left(\mathrm{~kJ} \cdot \mathrm{mol}^{-1}\right)$ & $\Delta S\left(\mathrm{~kJ} \cdot \mathrm{K}^{-1} \cdot \mathrm{mol}^{-1}\right)$ \\
\hline 25 & -29.29 & 16.23 & 0.1520 \\
30 & -29.71 & & \\
35 & -30.91 & & \\
40 & -31.43 & & \\
\hline
\end{tabular}

\subsubsection{Recyclability of the adsorbent}

The material collected after the adsorption experiments can be reused following a thermal treatment at $550{ }^{\circ} \mathrm{C}$ for $4 \mathrm{~h}$ under an oxygen atmosphere. Fig. 3b shows that this temperature value is suitable for the adsorbed AY decomposition. Besides, the adsorbent can be recycled if heated at $550^{\circ} \mathrm{C}$ with a crystalline structure similar to that of the sample calcined previously.

The capacity of AY to adsorb onto CLDH was tested in five regeneration cycles (Fig. 9). After the first use, the adsorption capacity reached $100,98.9,90.1$ and $62.5 \%$ of the initial capacity. Crepaldi et al. (2002) also reported the possibility of regeneration of CLDH after terephthalate adsorption with only a small and gradual reduction in adsorption capacity, indicating an important ecoefficient property (Crepaldi et al., 2002). The decrease of the adsorption values can be explained by the progressive loss of crystallinity during the recovery of the precursor materials as well the incorporation of certain amounts of decomposition compounds of azo dye in the regenerated materials (Zhu et al., 2005).

\section{Conclusion}

The $\mathrm{Mg}-\mathrm{Al}-\mathrm{CO}_{3}-\mathrm{LDH}$ was prepared by coprecipitation at constant $\mathrm{pH}$ value. The XRD for this material showed the presence of characteristic basal reflections for the formation of $\mathrm{Mg}-\mathrm{Al}-\mathrm{CO}_{3}-\mathrm{LDH}$ with a interlayer space of $7.65 \AA$. The XRD pattern of calcined LDH showed typical peaks of MgO phase. For RLDH sample recovered after the azo dye adsorption, the diffraction pattern showed a phase with the presence of basal reflections related to the intercalation of azo dye AY42, with a interlayer space of $20.02 \AA$, and the other phase with basal reflections related to the intercalation of hydroxide or carbonate ions, with a basal space of $7.54 \AA$.

The adsorption capacity of calcined sample (CLDH) was almost four times greater than that of the precursor material, $1265.9 \mathrm{mg} \cdot \mathrm{g}^{-1}$ $\left(1.67 \mathrm{mmol} \cdot \mathrm{g}^{-1}\right)$ and $330.033 \cdot \mathrm{mg} \mathrm{g}^{-1}\left(0.435 \mathrm{mmol} \cdot \mathrm{g}^{-1}\right)$, respectively. The adsorption isotherms fitted best to the Langmuir model. Kinetic experiments showed that the concentration reaches steady state equilibrium between 240 and $360 \mathrm{~min}$, depending on the dye solution concentration, and the kinetic models showed that the adsorption rate is

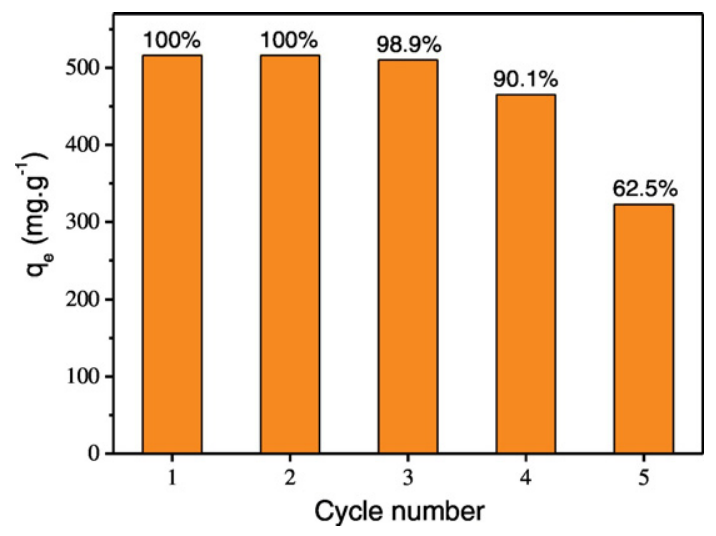

Fig. 9. Recycling of the adsorbent CLDH after azo dye adsorption, $C_{0}=250 \mathrm{mg} \cdot \mathrm{g}^{-1}$ at $25{ }^{\circ} \mathrm{C}$. controlled by the chemisorption. Though the calcination method is not environmentally friendly as it produces air pollution and consumes a lot of energy, the recycling of the material for reuse after azo dye adsorption showed good efficacy in up to five cycles of recyclability.

\section{Acknowledgements}

This study was supported by the Fundação de Amparo à Pesquisa do Estado de Minas Gerais - FAPEMIG (APQ-00341-08, APQ-00706-11, APQ-00113-14), Rede Mineira de Química - RQ-MG (CEX - RED00010-14), and Conselho Nacional de Desenvolvimento Científico e Tecnológico - CNPq (502835/2009-5). The authors are also thankful to Fapemig and CNPq for the fellowships. We would also like to thank the laboratory of the "Grupo de Espectroanalítica e Automação" (GEA) for the metal analysis.

\section{Appendix A. Supplementary data}

Supplementary data to this article can be found online at http://dx. doi.org/10.1016/j.clay.2017.02.005.

\section{References}

Asouhidou, D.D., Triantafyllidis, K.S., Lazaridis, N.K., Matis, K.A., 2012. Adsorption of reactive dyes from aqueous solutions by layered double hydroxides. J. Chem. Technol. Biotechnol. 87, 575-582.

Auxilio, A.R., Andrews, P.C., Junk, P.C., Spiccia, L., 2009. The adsorption behavior of C.I. Acid Blue 9 onto calcined Mg-Al layered double hydroxides. Dyes Pigments 81, 103-112.

Baskaran, T., Christopher, J., Sakthivel, A., 2015. Progress on layered hydrotalcite (HT) materials as potential support and catalytic materials. RSC Adv. 5, 98853-98875.

Benselka-Hadj Abdelkader, N., Bentouami, A., Derriche, Z., Bettahar, N., de Ménorval, L.C. 2011. Synthesis and characterization of Mg-Fe layer double hydroxides and its application on adsorption of Orange G from aqueous solution. Chem. Eng. J. 169, 231-238.

Constantino, V.R.L., Pinnavaia, T.J., 1995. Basic properties of $\mathrm{Mg}^{2+}{ }_{1-\mathrm{x}} \mathrm{Al}^{3+}{ }_{\mathrm{x}}$ layered double hydroxides intercalated by carbonate, hydroxide, chloride, and sulfate anions. Inorg. Chem. 34, 883-892.

Crepaldi, E.L., Tronto, J., Cardoso, L.P., Valim, J.B., 2002. Sorption of terephthalate anions by calcined and uncalcined hydrotalcite-like compounds. Colloids Surf. A Physicochem. Eng. Asp. 211, 103-114.

Darmograi, G., Prelot, B., Layrac, G., Tichit, D., Martin-Gassin, G., Salles, F., Zajac, J., 2015 Study of adsorption and intercalation of orange-type dyes into $\mathrm{Mg}$-Al layered double hydroxide. J. Phys. Chem. C 119, 23388-23397.

Deng, L., Shi, Z., Peng, X., Zhou, S., 2016. Magnetic calcinated cobalt ferrite/magnesium aluminum hydrotalcite composite for enhanced adsorption of methyl orange. J. Alloys Compd. 688, 101-112.

Dos Reis, M.J., Silvério, F., Tronto, J., Valim, J.B., 2004. Effects of pH, temperature, and ionic strength on adsorption of sodium dodecylbenzenesulfonate into $\mathrm{Mg}-\mathrm{Al}-\mathrm{CO}_{3}$ layered double hydroxides. J. Phys. Chem. Solids 65, 487-492.

Drici Setti, N., Jouini, N., Derriche, Z., 2010. Sorption study of an anionic dye benzopurpurine $4 \mathrm{~B}$ - on calcined and uncalcined $\mathrm{Mg}$-Al layered double hydroxides. J. Phys. Chem. Solids 71, 556-559.

El Gaini, L., Lakraimi, M., Sebbar, E., Meghea, A., Bakasse, M., 2009. Removal of indigo carmine dye from water to $\mathrm{Mg}$-Al- $\mathrm{CO}_{3}$-calcined layered double hydroxides. J. Hazard. Mater. 161, 627-632.

Extremera, R., Pavlovic, I., Pérez, M.R., Barriga, C., 2012. Removal of acid orange 10 by calcined $\mathrm{Mg} / \mathrm{Al}$ layered double hydroxides from water and recovery of the adsorbed dye. Chem. Eng. J. 213, 392-400.

Forano, C., Costantino, U., Prévot, V., Taviot-Guého, C., 2013. Handbook of clay science. In: Bergaya, F., Lagaly, G. (Eds.), Developments in Clay Science. Elsevier, Amsterdam, pp. 745-782.

Guo, Y., Zhu, Z., Qiu, Y., Zhao, J., 2013. Enhanced adsorption of acid brown 14 dye on calcined Mg/Fe layered double hydroxide with memory effect. Chem. Eng. J. 219, 69-77.

Gupta, V.K., Suhas, 2009. Application of low-cost adsorbents for dye removal - a review. J. Environ. Manag. 90, 2313-2342.

Jia, Z., Li, S., Liu, J., Qin, Q.I., Zhu, R., 2015. Synthesis of MgAl-LDH/ $\mathrm{CoFe}_{2} \mathrm{O}_{4}$ and $\mathrm{MgAl}$ $\mathrm{CLDH} / \mathrm{CoFe}_{2} \mathrm{O}_{4}$ nanofibres for the removal of Congo Red from aqueous solution. Bull. Mater. Sci. 38, 1757-1764.

Koilraj, P., Takaki, Y., Sasaki, K., 2016. Adsorption characteristics of arsenate on colloida nanosheets of layered double hydroxide. Appl. Clay Sci. 134, 110-119.

Li, B., Zhang, Y., Zhou, X., Liu, Z., Liu, Q., Li, X., 2016. Different dye removal mechanisms between monodispersed and uniform hexagonal thin plate-like $\mathrm{MgAl}-\mathrm{CO}_{3}^{2-}-\mathrm{LDH}$ and its calcined product in efficient removal of Congo red from water. J. Alloys Compd. 673, 265-271.

Lu, H., Zhu, Z., Zhang, H., Zhu, J., Qiu, Y., 2015. Simultaneous removal of arsenate and antimonate in simulated and practical water samples by adsorption onto $\mathrm{Zn} / \mathrm{Fe}$ layered double hydroxide. Chem. Eng. J. 276, 365-375.

Ni, Z.M., Xia, S.J., Wang, L.G., Xing, F.F., Pan, G.X., 2007. Treatment of methyl orange by calcined layered double hydroxides in aqueous solution: adsorption property and kinetic studies. J. Colloid Interface Sci. 316, 284-291. 
Pavan, P.C., Crepaldi, E.L., De Gomes, G.A., Valim, J.B., 1999. Adsorption of sodium dodecylsulfate on a hydrotalcite-like compound. Effect of temperature, $\mathrm{pH}$ and ionic strength. Colloids Surf. A Physicochem. Eng. Asp. 154, 399-410.

Robinson, T., McMullan, G., Marchant, R., Nigam, P., 2001. Remediation of dyes in textile effluent: a critical review on current treatment technologies with a proposed alternative. Bioresour. Technol. 77, 247-255.

Roelofs, J.C.A.A., Van Bokhoven, J.A., Van Dillen, A.J., Geus, J.W., De Jong, K.P., 2002. The thermal decomposition of Mg-A1 hydrotalcites: effects of interlayer anions and characteristics of the final structure. Chem. Eur. J. 8, 5571-5579.

Santos, R.M.M., Gonçalves, R.G.L., Constantino, V.R.L., da Costa, L.M., da Silva, L.H.M., Tronto, J., Pinto, F.G., 2013. Removal of Acid Green 68:1 from aqueous solutions by calcined and uncalcined layered double hydroxides. Appl. Clay Sci. 80-81, 189-195.

Shan, R. Ran, Guo Yan, L., Yang Ming, Y., Yang, K., Jun Yu, S., Qin Yu, H., Cun Zhu, B., Du, B. 2015. Highly efficient removal of three red dyes by adsorption onto Mg-Al-layered double hydroxide. J. Ind. Eng. Chem. 21, 561-568.

Tan, K.B., Vakili, M., Horri, B.A., Poh, P.E., Abdullah, A.Z., Salamatinia, B., 2015. Adsorption of dyes by nanomaterials: recent developments and adsorption mechanisms. Sep. Purif. Technol. 150, 229-242.

Teixeira, T.P.F., Pereira, S.I., Aquino, S.F., Dias, A., 2012. Calcined layered double hydroxides for decolorization of azo dye solutions: equilibrium, kinetics, and recycling studies. Environ. Eng. Sci. 29, 685-692.
Thomas, G.S., Radha, A.V., Kamath, P.V., Kannan, S., 2006. Thermally induced polytype transformations among the layered double hydroxides (LDHs) of $\mathrm{Mg}$ and $\mathrm{Zn}$ with Al. J. Phys. Chem. B 110, 12365-12371

Yang, F., Sun, S., Chen, X., Chang, Y., Zha, F., Lei, Z., 2016. Mg-Al layered double hydroxides modified clay adsorbents for efficient removal of $\mathrm{Pb}^{2+}, \mathrm{Cu}^{2+}$ and $\mathrm{Ni}^{2+}$ from water. Appl. Clay Sci. 123, 134-140.

Yu, Q., Zheng, Y., Wang, Y., Shen, L., Wang, H., Zheng, Y., He, N., Li, Q., 2015. Highly selective adsorption of phosphate by pyromellitic acid intercalated ZnAl-LDHs: assembling hydrogen bond acceptor sites. Chem. Eng. J. 260, 809-817.

Zhang, Y.X., Hao, X.D., Wang, T., Meng, Y.X., Han, X., 2014. $\mathrm{MnO}_{(\mathrm{x})}$-modified ZnAl-LDOs as high-performance adsorbent for the removal of methyl orange. Dalton Trans. 43, 6667-6676.

Zhao, P., Liu, X., Tian, W., Yan, D., Sun, X., Lei, X., 2015. Adsolubilization of 2,4,6trichlorophenol from aqueous solution by surfactant intercalated ZnAl layered double hydroxides. Chem. Eng. J. 279, 597-604.

Zheng, Y.M., Li, N., Zhang, W. De, 2012. Preparation of nanostructured microspheres of Zn$\mathrm{Mg}$-Al layered double hydroxides with high adsorption property. Colloids Surf. A Physicochem. Eng. Asp. 415, 195-201.

Zhu, M.X., Li, Y.P., Xie, M., Xin, H.Z., 2005. Sorption of an anionic dye by uncalcined and calcined layered double hydroxides: a case study. J. Hazard. Mater. 120, 163-171. 